\title{
Bioactivity-Guided Investigation of the Anti-Inflammatory Activity of Hippophae rhamnoides Fruits
}

\author{
Authors \\ Affiliations \\ 1 Department of Pharmacognosy, University of Szeged, \\ Szeged, Hungary \\ 2 Department of Pharmacodynamics and Biopharmacy, \\ University of Szeged, Szeged, Hungary \\ 3 Interdisciplinary Center of Natural Products, University of \\ Szeged, Szeged, Hungary \\ Key words \\ Hippophae rhamnoides, Elaeagnaceae, paw edema, oleanolic \\ acid, ursolic acid, lignans \\ $\begin{array}{ll}\text { received } & \text { January } 31,2017 \\ \text { revised } & \text { May 18, } 2017 \\ \text { accepted } & \text { June 9, } 2017\end{array}$ \\ Bibliography \\ DOI https://doi.org/10.1055/s-0043-114424 \\ Published online June 29, 2017 | Planta Med 2018; 84: 26-33 \\ (c) Georg Thieme Verlag KG Stuttgart · New York I \\ ISSN 0032-0943 \\ Correspondence \\ Prof. Dr. Judit Hohmann \\ Department of Pharmacognosy, University of Szeged \\ Eötvös u. 6, 6720 Szeged, Hungary \\ Phone: + 3662546451, Fax: + 3662545704 \\ hohmann@pharm.u-szeged.hu
}

Dóra Rédei ${ }^{1}$, Norbert Kúsz ${ }^{1}$, Nikoletta Jedlinszki ${ }^{1}$, Gábor Blazsó ${ }^{2}$, István Zupkó ${ }^{2,3}$, Judit Hohmann ${ }^{1,3}$

Supporting information available online at

http://www.thieme-connect.de/products

\section{ABSTRACT}

According to modern ethnobotanical records, the fruit of Hippophae rhamnoides is effective in the treatment of different allergic symptoms. In order to obtain pharmacological evidence for this observation, the fruit was investigated for anti-inflammatory activity using in vivo animal models. Aqueous and $70 \%$ $\mathrm{MeOH}$ extracts were tested in 48/80-induced rat paw edema assay after oral administration, and it was found that the $70 \%$ $\mathrm{MeOH}$ extract $(500 \mathrm{mg} / \mathrm{kg})$ reduced significantly edema volume $(0.660 \pm 0.082 \mathrm{~mL}$ vs. control $0.935 \pm 0.041 \mathrm{~mL})$. Extracts of different parts of the fruit (pulp, peel, seed) were investigated in the same assay, and the peel extract was shown to exhibit maximum edema-reducing effect $(0.470 \pm 0.124 \mathrm{~mL}$ vs. control $0.920 \pm 0.111 \mathrm{~mL}$ ). This extract was used to elucidate the mode of action. Different inflammation inducers (serotonin, histamine, dextran, bradykinin, and carrageenan) were applied in the rat paw model, but the extract inhibited only the compound 48/80 elicited inflammation. The active extract was then fractionated by solvent-solvent partitioning and chromatographic methods with the guidance of the 48/ 80 -induced anti-inflammatory assay, and the main compounds responsible for the activity were identified as ursolic acid and oleanolic acid. Our data suggest that the activity is most probably based on a membrane stabilizing effect caused by the inhibition of degranulation of mast cells. Moreover, previously unknown 2,5-bis-aryl-3,4-dimethyltetrahydrofuran lignans, nectandrin $\mathrm{B}$, fragransin $\mathrm{A}_{2}$, and saucernetindiol were isolated and identified from $\mathrm{H}$. rhamnoides for the first time.

\section{Introduction}

Hippophae rhamnoides L. (sea buckthorn) belongs to the family Elaeagnaceae and is native to China, Russia, Mongolia, and Siberia. Nowadays it is cultivated in many countries of Europe and Asia. Different parts of the shrub, especially the berries, have been used for medicinal and nutritional purposes in the Baltic region and by Tibetan and Mongolian people. Preparations of sea buckthorn are commonly employed in folk medicine for the treatment of gastric disorders, liver injury, asthma, cardiovascular problems, and skin diseases. Further, in Europe and Central Asia, every part of the plant (berries, leaves, young shoots, roots, and bark) is utilized as food, firewood, fuel, feed, or decoration [1,2].
H. rhamnoides has been widely studied for bioactive constituents, and flavonoids, carotenoids, essential oil, vitamins, carbohydrates, organic acids, amino acids, and micro- and macronutrients have been detected from different plant parts. Many bioactive compounds were isolated from the berries, such as hippophae cerebroside, triterpene acids, furanoaldehydes, isorhamnetin and quercetin glycosides, tannins, saturated and unsaturated fatty acids, and fatty acid glycerides [3]. Further interesting metabolites are carotenoid-lipoprotein complexes and polysaccharides, which are in the focus of phytochemical-pharmacological research because of their physiological function and acute liver injury preventive effect [2]. Significant antioxidant activities of the fruit were demonstrated in antioxidant assays in consequence of 


$\begin{array}{ll}\text { ABBREVIATIONS } \\ \text { HFWE } & \text { Hippophae fruits water extract } \\ \text { HFME } & \text { Hippophae fruits } 70 \% \mathrm{MeOH} \text { extract } \\ \text { HPuME } & \text { Hippophae pulp } 70 \% \mathrm{MeOH} \text { extract } \\ \text { HSME } & \text { Hippophae seed } 70 \% \mathrm{MeOH} \text { extract } \\ \text { HPeME } & \text { Hippophae peel } 70 \% \mathrm{MeOH} \text { extract } \\ \text { HPeCE } & \text { Hippophae peel } \mathrm{CHCl}_{3} \text { extract } \\ \text { HPeEE } & \text { Hippophae peel ethyl acetate extract } \\ \text { HPeBE } & \text { Hippophae peel } n \text {-butanol extract } \\ \text { HPeER } & \text { Hippophae peel extracts remnant } \\ \text { HPeCF } & \text { Hippophae peel extracts } \mathrm{CHCl}_{3} \text { fraction } \\ \text { VLC } & \text { vacuum liquid chromatography }\end{array}$

its high vitamin C (600 mg/100 g fruit), vitamin E content, and flavonoid components. Recent studies have shown that constituents of sea buckthorn are considered to be promising compounds in the treatment of cancer, gastric ulcer, skin diseases, thrombosis, and diabetes [1]. Moreover, antiviral and antibacterial effects were reported for the aqueous seed extract and hiporamin, a purified polyphenol fraction of the leaves [3].

The anti-inflammatory activity in various experimental models of inflammation has been documented. The $70 \% \mathrm{EtOH}$ extracts of the branches of $\mathrm{H}$. rhamnoides showed inhibitory effects on 12-Otetradecanoylphorbol-13-acetate (TPA) induced ear edema in mice [4]. (-)-Epigallocatechin and ursolic acid were isolated and identified as compounds responsible for anti-inflammatory activity. Liu et al. [2] studied the polysaccharide fraction isolated from the berries and found that its anti-inflammatory effect is mediated by blocking NF- $\kappa$ B activation. Yuan et al. [5] investigated the protein fraction obtained from the seed and concluded that seed protein diet can significantly reduce inflammatory factor levels in diabetic mice. In the study of Park et al. [6], the activity-guided fractionation of dichloromethane fraction of the stems resulted the identification of $\beta$-sitosterol as an anti-inflammatory agent; this compound strongly inhibited the production of nitrite in RAW 264.7 cells compared to only lipopolysaccharide treatment.

In accordance with the above scientific and folk medicinal information, sea buckthorn berries are widely used as food supplements, additives, cosmetic ingredients, or nutraceuticals. In addition, in the recent years a new application is spreading through the Internet in Hungary. It is claimed that sea buckthorn preparations are effective in reduction of allergic symptoms, caused by pollens, metals, or sunburn. The dried fruit mixed with yogurt, muesli, or other food is recommended for the alleviation of sneezing, nasal congestion, cough, itchy skin, watery eyes, runny nose, hives, and irritability $[7,8]$. The information is propagated on forums and in product advertisements, and some medical doctors also advise for their patients the use of sea buckthorn fruit for the treatment of allergic symptoms. The aim of the present work was the validation of this observation and investigation of the fruits of $H$. rhamnoides for anti-inflammatory activity using in vivo animal models. Different parts of the fruit and extracts prepared by different solvents were analyzed, and from the most active
$\mathrm{CHCl}_{3}$ fraction of the $\mathrm{MeOH}$ peel extract, the compounds responsible for the activity were identified by activity-guided isolation procedure.

\section{Results}

According to modern ethnobotanical records, the fruits of $H$. rhamnoides were effective in the treatment of different allergic symptoms. In order to obtain pharmacological evidence for this observation, the fruits were investigated for their anti-inflammatory activity using in vivo rat paw models.

First, aqueous (HFWE) and 70\% MeOH (HFME) extracts were prepared from the whole fruits of $H$. rhamnoides and tested in the 48/80-induced rat paw edema model after oral administration. HFME showed interesting anti-inflammatory activity and reduced the edema volume $(0.660 \pm 0.082 \mathrm{~mL}$ vs. control $0.935 \pm$ $0.041 \mathrm{~mL})$, while HFWE had no significant effect $(0.874 \pm$ $0.130 \mathrm{~mL}$ ) ( Fig. 1).

With regard to the significantly different chemical composition, different parts of the fruits were investigated separately, and aqueous $\mathrm{MeOH}$ extracts were prepared from the pulp (HPuME), peel (HPeME), and seeds (HSME) in order to find the most active part of the berries. HPuME exerted no significant action on the formation of 48/80-induced rat paw edema ( $\bullet$ Fig. 2 ). HPeME exhibited the highest anti-inflammatory effect. HSME produced a moderate $(0.760 \pm 0.111 \mathrm{~mL}$ vs. $0.920 \pm 0.111 \mathrm{~mL})$ but significant $(p<0.05)$ reduction of rat paw volume.

In order to investigate the possible mechanism of edema inhibitory effect of the most active extract, HPeME was tested in different inflammatory models. In this set of experiments, serotonin, histamine, dextran, bradykinin, and carrageenan were additionally used as edema inducers. It was established that oral administration of $500 \mathrm{mg} / \mathrm{kg}$ HPeME was ineffective if edema was induced by serotonin, histamine, dextran, bradykinin, or carrageenan ( $\triangleright$ Fig. 3). In case of compound 48/80-induced edema, however, HPeME inhibited significantly $(0.470 \pm 0.124 \mathrm{~mL}$ vs. $0.920 \pm$ $0.111 \mathrm{~mL}, \mathrm{p}<0.001$ ) edema formation.

Solvent-solvent partitioning was used to gain $\mathrm{CHCl}_{3}$ (HPeCE), ethyl acetate (HPeEE), n-butanol (HPeBE), and water soluble (HPeER) fractions of HPeME with the aim to identify the active constituents ( $\bullet$ Fig. 4 ). The anti-inflammatory activity of HPeCE, HPeEE, HPeBE, and HPeER was investigated in the 48/80-induced rat paw edema model ( $\triangleright$ Fig.5). Edema inhibitory activities of fractions containing moderate apolar components (HPeEE, HPeBE, and HPeER) were not statistically different from the values of the control. Volume of paw edema after oral administration of the lipophilic fraction HPeCE $(500 \mathrm{mg} / \mathrm{kg})$ was significantly reduced $(0.362 \pm 0.103 \mathrm{~mL}, \mathrm{p}<0.01)$ compared to those in the control group $(0.644 \pm 0.059 \mathrm{~mL})$. All these findings suggested that the anti-inflammatory agents of sea buckthorn fruits are concentrated in the peel of the berries and have lipophilic character.

For bioactivity-guided isolation $\mathrm{CHCl}_{3}$ soluble fraction $(27 \mathrm{~g}$, $0.9 \%$ of peel) (HPeCF) was prepared from the $70 \% \mathrm{MeOH}$ extract of dried peel and submitted to VLC on silica gel using gradient system of $n$-hexane-acetone, to yield fractions A1-20, A21-31, A32-41, A42-49, A50-55, A56-61, and A62-68, respectively ( $\triangleright$ Fig. 6). After testing the fractions in the paw edema model, it 
was established that fraction A32-41 had a similar significant activity as HPeCF (edema volume $0.432 \pm 0.079 \mathrm{~mL}$ and $0.440 \pm$ $0.128 \mathrm{~mL}$, vs. control $0.855 \pm 0.067 \mathrm{~mL}, \mathrm{p}<0.001$ ) ( $\triangleright$ Fig. 7). All other fractions proved to be inactive. The thin layer chromatogram of fractions suggested that component at $R_{f}=0.73$ represents the major compound of the active fraction (A32-41) (Fig. 1S, Supporting Information). After repeated purification by VLC on RP-18, a mixture of two compounds was obtained (besides a fraction without these compounds). On the basis of structure elucidation using ${ }^{1} \mathrm{H}$ and ${ }^{13} \mathrm{C}$ NMR measurements and MS spectra, the two compounds were identified as oleanolic acid and ursolic acid based on the data identical with those reported in $\mathrm{Hu}$ et al. and Gnaotto et al. [9, 10].

The concentrations of triterpenes were measured by HPLC-UV method. It was established that fraction A32-41 contained $30.76 \%$ oleanolic acid and $19.11 \%$ ursolic acid. Accordingly, the calculated oleanolic acid-ursolic acid ratio in fraction B16-19/ C11-16 was 154:96. Anti-inflammatory activity of the main components oleanolic acid and ursolic acid, their mixture (ratio 154:96), and fraction B1-9/C1-10 (other compounds) were tested in the paw edema model using different doses imitating the composition of fraction A32-41. Oleanolic acid (154 mg/kg), ursolic acid $(96 \mathrm{mg} / \mathrm{kg})$, and their mixture $(154: 96,250 \mathrm{mg} / \mathrm{kg}$ ) significantly reduced the edema volume $(0.600 \pm 0.055 \mathrm{~mL}$, $0.688 \pm 0.102 \mathrm{~mL}, \quad 0.452 \pm 0.080 \mathrm{~mL}$, vs. control $0.862 \pm$ $0.097 \mathrm{~mL}$ ), while the fraction containing other compounds (fraction B1-9/C1-10) had no significant effect $(0.920 \pm 0.087 \mathrm{~mL})$ $(\vee$ Fig. 8), proving that the triterpene acids are the active ingredients.

Fraction A42-49, which showed some overlap in composition with fraction A32-41, was subjected to multiple chromatographic separations to afford the isolation of lignans $1-3$. Compound 1 was identified as nectandrin B [11], compound 2 was identical in all of its spectral characteristics with fragransin $A_{2}$ [12]. Compound 3 was identical with saucernetindiol [13] ( $\triangleright$ Fig. 9). The NMR data of these compounds in $\mathrm{CD}_{3} \mathrm{OD}$ (Table 1S, Supporting Information) are reported here for the first time. In addition, by crystallization from $\mathrm{MeOH}$, fractions A50-55 and A56-61 afforded isorhamnetin.

\section{Discussion}

Sea buckthorn has been used globally as therapeutic and healthpromoting agent and is regarded as a "superfood" because of its powerful antioxidant effects, high vitamin $\mathrm{C}$ contents, and richness in polyunsaturated fatty acids. In recent years in Hungary, the fruit of the plant has been advertised as an effective herbal product for the treatment of allergic symptoms. In our experiment, the anti-inflammatory activity of the berry was studied using in vivo rat paw edema models. The inflammation-reducing activity of the $70 \% \mathrm{MeOH}$ extract was confirmed in the 48/80-induced rat paw edema test, which is a standard model of mast cell degranulation-implicated inflammatory processes. The highest activity was recorded for the peel extract, when $70 \% \mathrm{MeOH}$ extracts of different parts of sea buckthorn fruit (peel, pulp, and seed) were evaluated. The peel is often considered as the by-product of food processing (e.g., juice pressing).

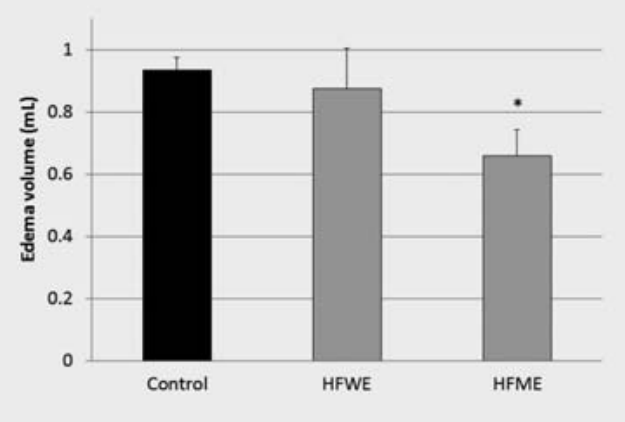

- Fig. 1 Effect of the p. o. administration of water (HFWE) extract or $70 \% \mathrm{MeOH}$ extract (HFME) $(500 \mathrm{mg} / \mathrm{kg})$ on $48 / 80$-induced rat paw edema (mean \pm SD; ${ }^{*} p<0.05$ as compared with the control).

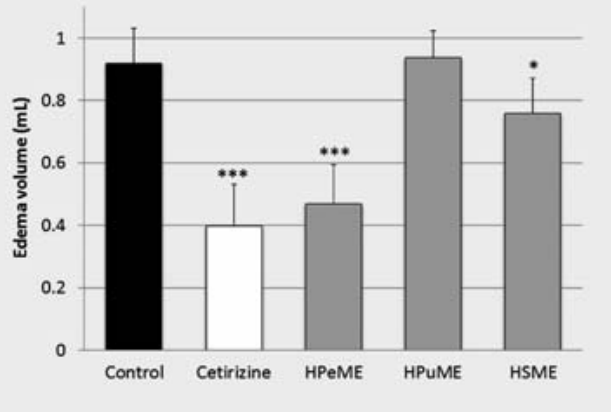

- Fig. 2 Effect of the p. o. administration of cetirizine $(50 \mathrm{mg} / \mathrm{kg})$ or $70 \% \mathrm{MeOH}$ extract of peel (HPEME), pulp (HPuME), and seeds (HHSME) $(500 \mathrm{mg} / \mathrm{kg})$ on 48/80-induced rat paw edema (mean \pm SD; ${ }^{*} \mathrm{p}<0.05,{ }^{* * *} \mathrm{p}<0.001$ as compared with the control).

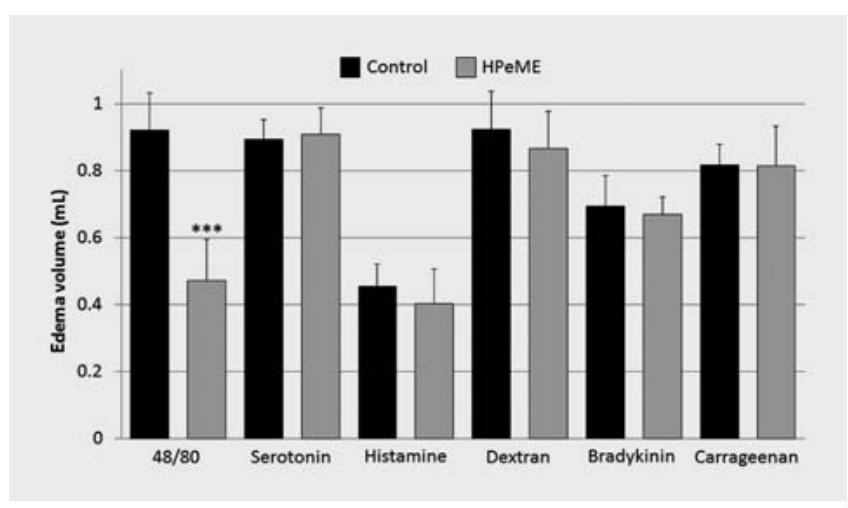

- Fig. 3 Effect of the p.o. administration of $\mathrm{MeOH}$ peel extract (HPeME) $(500 \mathrm{mg} / \mathrm{kg})$ on rat paw edema induced by different proinflammatory agents (48/80, serotonin, histamine, dextran, bradykinin, carrageenan) (mean $\pm \mathrm{SD} ;{ }^{* * *} \mathrm{p}<0.001$ as compared with the control). 


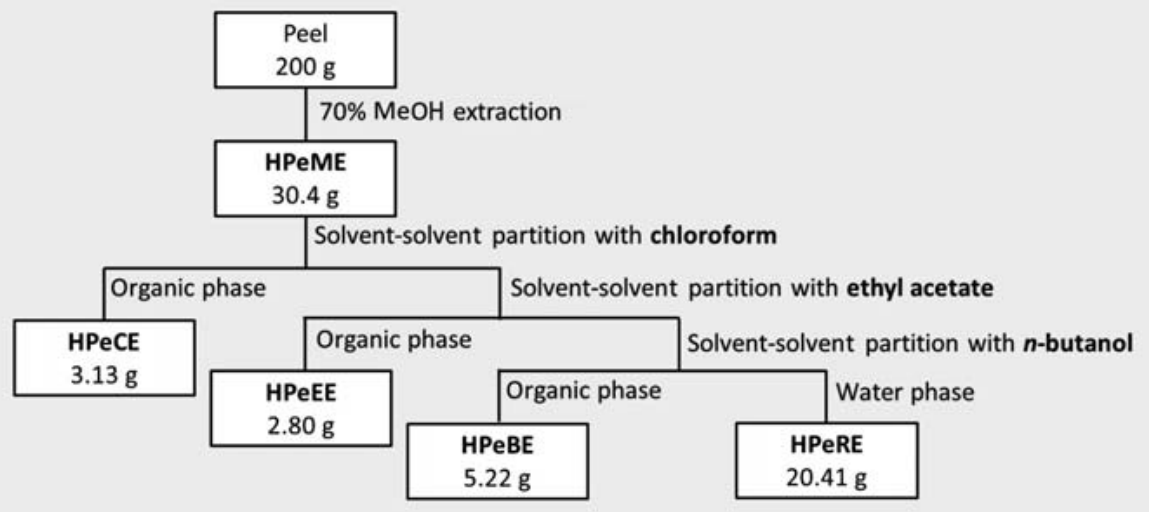

- Fig. 4 Scheme of preparing of extracts HPeME, HPeCE, HPeEE, HPeBE, and HPeER.

The fruit peel extract inhibited only the 48/80-induced inflammation, and inflammation caused by other edema inducers (serotonin, histamine, dextran, bradykinin and carrageenan) was not reduced by the fruit peel extract (HPeME). The inflammation elicited by compound $48 / 80$ is considered a consequence of the release of endogenously produced and stored histamine from mast cells [14]. The other applied agents are either exogenous mediators of the pro-inflammatory reaction (bradykinin, serotonin, and histamine) or polysaccharide-type inducers (carrageenan, dextran) eliciting a more complex mechanism involving bradykinin, histamine, tachykinins, reactive oxygen, and nitrogen species [15]. The basic difference of these mechanisms supports the possible benefit of $H$. rhamnoides in the treatment of allergic symptoms, in accordance with recent ethnobotanical observation.

Ursolic acid and oleanolic acid were identified as the main compounds responsible for the activity with the guidance of the 48/80-induced anti-inflammatory assay from the active apolar fraction of $\mathrm{MeOH}$ peel extract by solvent-solvent partition and chromatographic purifications. The pure triterpene acids unequivocally accounted for the anti-inflammatory effect of the fruit peel extract, but other active compounds may also be present in smaller concentrations. Regarding the mechanism of action, it is supposed that the measured activity of triterpene acids is based on membrane stabilizing effect caused by inhibition of the degranulation of mast cells.

Isolation of ursolic acid and oleanolic acid was reported already from the fruits of $H$. rhamnoides [16]. Ursolic acid was also obtained from the extract of branches of the plant [4]. Their anti-inflammatory activity was demonstrated by several studies. It was found that ursolic acid and oleanolic acid have TPA-induced inflammation inhibitory activity in the mouse ear edema test [15, 17]. Significant COX-2-inhibiting activity of ursolic acid was demonstrated in in vitro COX-2-catalyzed prostaglandin biosynthesis assay with a COX-2/COX-1 selectivity ratio of 0.6 . This activity was observed in COX-2 TPA-treated human mammary and oral epithelial cells. Oleanolic acid exhibited inhibitory effects on carrageenan-induced rat paw edema and formalin-induced arthritis [18]. Despite of these studies, the in vivo anti-inflammatory effect of orally applied compounds on 48/80-induced edema model was

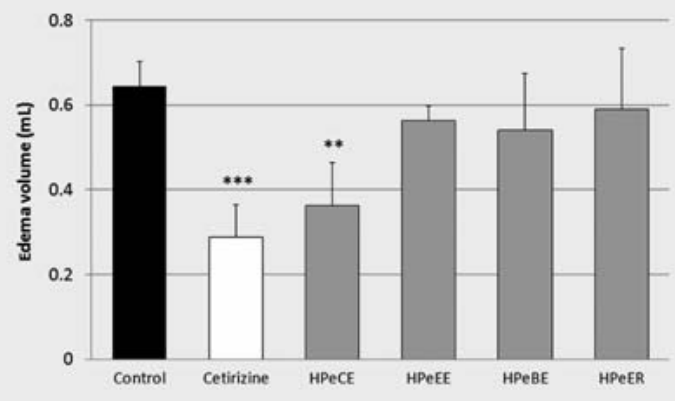

- Fig. 5 Effect of the p.o. administration of cetirizine $(50 \mathrm{mg} / \mathrm{kg})$ or $\mathrm{CHCl}_{3}$ (HPeCE), ethyl acetate (HPeEE), $n$-butanol (HPeBE), and water peel extract (HPeER) $(500 \mathrm{mg} / \mathrm{kg})$ on $48 / 80$-induced rat paw edema (mean $\pm \mathrm{SD} ;{ }^{* *} \mathrm{p}<0.01,{ }^{* * *} \mathrm{p}<0.001$ as compared with the control).

not reported previously. In accordance with our results, the antiinflammatory effect of ursolic acid was observed in a rat mast cell bioassay, and it was found that this compound inhibited 48/80-induced histamine release by $95 \%$ and $26 \%$ at concentrations of $10^{-3} \mathrm{M}$ and $10^{-4} \mathrm{M}$, respectively [19].

The present phytochemical analysis also resulted in the isolation of isorhamnetin and 2,6-bis-aryl-tetrahydrofuran-type stereoisomeric lignans: nectandrin $B(1)$, fragransin $A_{2}(2)$, and saucernetindiol (3). This type of lignan was identified for the first time from sea buckthorn and from the Elaeagnaceae family. Previously, these compounds were reported from different Myristicaceae, Saururaceae, Magnoliaceae, Lauraceae, Piperaceae, and Poaceae species $[12,20]$. Previously, other types of lignan, secoisolariciresinol and matairesinol, were isolated from sea buckthorn berries, and both compounds were detected in seeds, fruit pulp, and peel [21]. Compounds 1-3 were minor components of the active extracts and fractions, and although most probably they have no anti-inflammatory activity, they may contribute to the therapeutic and health-promoting effect of $H$. rhamnoides preparations. In earlier studies, tetrahydrofuran lignans were shown to 


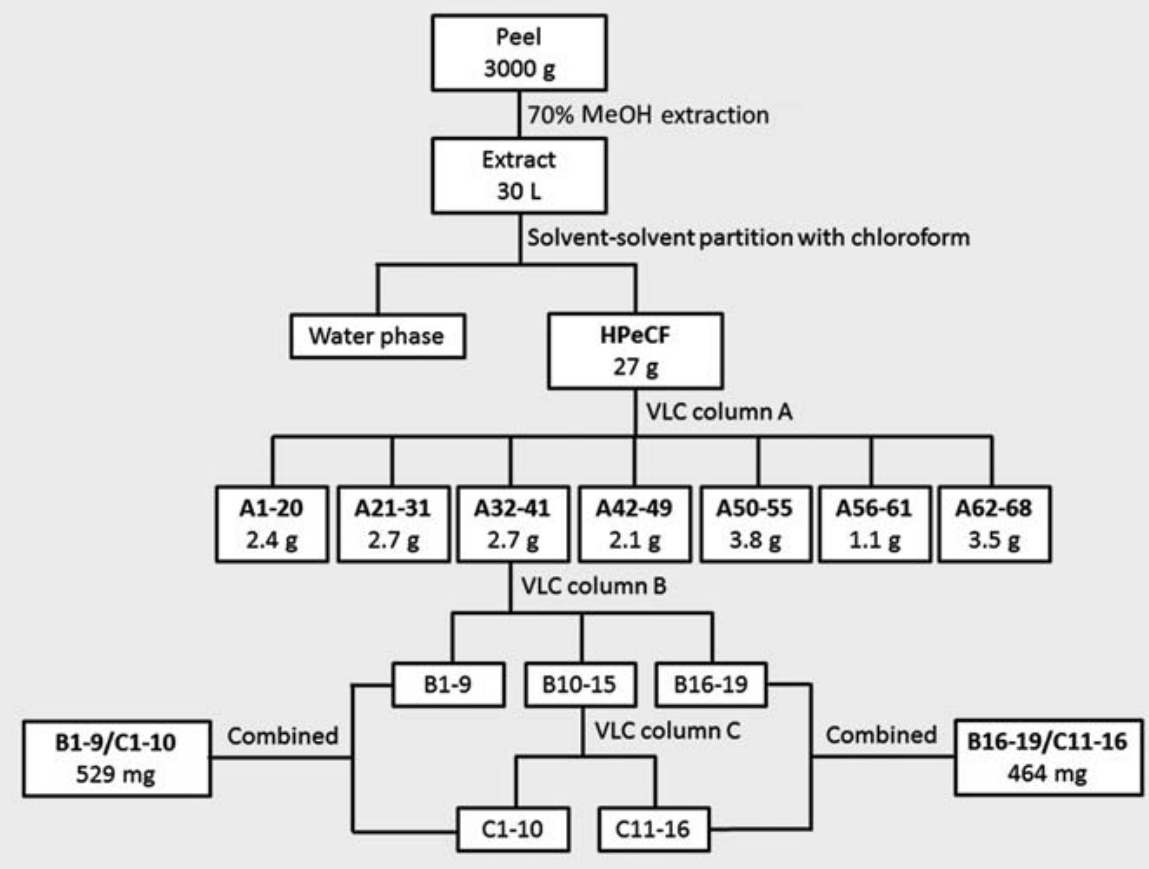

- Fig. 6 Scheme of bioactivity-guided isolation.

have high plant growth inhibitory potency against Italian ryegrass and against lettuce, and the inhibitory activity varied depending on the configurations of each position of the tetrahydrofuran ring [22]. Nectandrin B (1) was reported to have hepatocyte-protective effect against oxidative injury through the activation of the Nrf2/ARE pathway mediated by extracellular signal-regulated kinase phosphorylation and adenosine monophosphate activated protein kinase dependent inactivation of GSK-3 $\beta$ [23]. In addition, nectandrin B (1) suppresses the expression of adhesion molecules in endothelial cells, an initial event in atherogenesis [24]. Diaryldimethyl-tetrahydrofuran lignans, including nectandrin B (1), exert neurotrophic and neuroprotective effect, promoting neuronal survival and neurite outgrowth [25].

\section{Materials and Methods}

\section{General experiment procedures}

The optical rotation was determined in $\mathrm{CHCl}_{3}$ using a Perkin-Elmer 341 polarimeter. NMR spectra were recorded in $\mathrm{CDCl}_{3}$ and $\mathrm{CD}_{3} \mathrm{OD}$ on a Bruker Avance DRX 500 spectrometer at $500 \mathrm{MHz}\left({ }^{1} \mathrm{H}\right)$ and $125 \mathrm{MHz}\left({ }^{13} \mathrm{C}\right)$. The peak of the residual solvent were taken as reference. The data were acquired and processed with MestReNova v. 6.0.2-5475 software. Chemical shifts are expressed in parts per million, and coupling constant $(J)$ values are reported in $\mathrm{Hz}$. Low-resolution ESI mass spectra were recorded on an API 2000 triple quadrupole mass spectrometer equipped with an electrospray interface. Atmospheric pressure chemical ionization mass spectrometry (APCIMS) and electrospray ionization mass spectrometry (ESIMS) measurements were performed on an API 2000 LC-MS

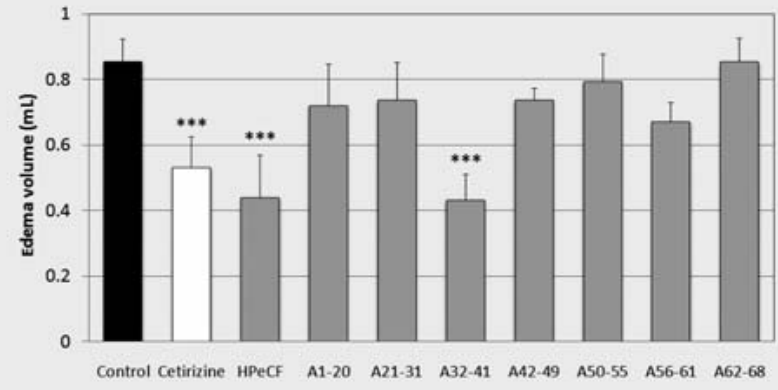

- Fig. 7 Effect of the p. o. administration of cetirizine $(50 \mathrm{mg} / \mathrm{kg})$ or $\mathrm{CHCl}_{3}$ fraction (HPeCF) and fractions A1-20 to A62-68 (500 mg $\left./ \mathrm{kg}\right)$ on $48 / 80$-induced rat paw edema (mean $\pm \mathrm{SD}$; ${ }^{* * *} \mathrm{p}<0.001$ as compared with the control).

system. For VLC, silica gel (TLC-Silica gel $60 \mathrm{GF}_{254}, 15 \mu \mathrm{m}$, Merck) and reversed phase silica gel (LiChroprep RP-18, 40-63 $\mu \mathrm{m}$, Merck) were used. Pre-coated normal phase silica gel plates (Silica gel $60 \mathrm{~F}_{254}, 0.25 \mathrm{~mm}$, Merck) and reversed phase silica gel plates (Silica gel 60 RP-18 $F_{254}$, Merck) were used for thin layer chromatography (TLC) analyses and preparative TLC. Spots were visualized by heating after spraying with concentrated $\mathrm{H}_{2} \mathrm{SO}_{4}$. HPLC measurements were performed on a Shimadzu LC-20 instrument. Results were calculated with Analist 1.4 software.

\section{Plant material}

$H$. rhamnoides was organically cultivated and harvested in Fajsz, Hungary. Fresh whole fruits, fresh pulp, dried peel, and dried 
seeds were donated by Bio-Drog-Berta Ltd. The plant was identified by Dr. Zoltán Berta. A voucher specimen has been deposited at the herbarium of the Institute of Pharmacognosy, University of Szeged (voucher no. 878).

\section{Preparing of extracts for pharmacological investigation}

The different plant materials (whole fruits, peel, pulp, and seeds) were crushed or grinded and extracted with the adequate solvent in ultrasonic bath $(3 \times 15 \mathrm{~min})$. The extracts were concentrated under reduced pressure and freeze-dried. Then $200 \mathrm{~g}$ fresh fruits, $200 \mathrm{~g}$ fresh pulp, $100 \mathrm{~g}$ dried seeds, and $100 \mathrm{~g}$ dried peel were extracted with $3 \times 200 \mathrm{~mL}$ water (HFWE), $3 \times 200 \mathrm{~mL} 70 \% \mathrm{MeOH}$ (HFME), $3 \times 200 \mathrm{~mL} 70 \% \mathrm{MeOH}$ (HPuME), $3 \times 200 \mathrm{~mL} 70 \% \mathrm{MeOH}$ (HSME), and $1 \times 300 \mathrm{~mL}$ and $2 \times 200 \mathrm{~mL} 70 \% \mathrm{MeOH}$ (HPeME) affording dry extracts HFWE (12.7 g), HFME (6.7 g), HPuME (6.9 g), HSME (12.7g), and HPeME (15.2 g), respectively. Dried peel $(200 \mathrm{~g})$ was extracted with $1 \times 1300 \mathrm{~mL}$ and $2 \times 600 \mathrm{~mL} 70 \%$ $\mathrm{MeOH}$. After concentration under reduced pressure (to $200 \mathrm{~mL}$ ), the extract was partitioned successively with $\mathrm{CHCl}_{3}(3 \times 150 \mathrm{~mL})$, ethyl acetate $(3 \times 150 \mathrm{~mL})$, and $n$-butanol $(3 \times 150 \mathrm{~mL})$. The extracts and the remnant were concentrated under reduced pressure affording extracts HPeCE (3.13 g), HPeEE ( $2.80 \mathrm{~g})$, HPeBE (5.22 g), and HPeER (20.41 g).

\section{Bioactivity-guided isolation}

Dried peel $(3000 \mathrm{~g})$ was percolated at room temperature with $70 \% \mathrm{MeOH}(30 \mathrm{~L})$. The crude extract was concentrated $(2 \mathrm{~L})$ and partitioned with $\mathrm{CHCl}_{3}(6 \times 1500 \mathrm{~mL})$. The $\mathrm{CHCl}_{3}$ fraction (HPeCF, $27 \mathrm{~g}$ ) was submitted to VLC on silica gel (15 $\mu \mathrm{m}$, Merck) column (A) using a step gradient of $n$-hexane-acetone $9: 1(600 \mathrm{~mL}), 8: 2$ $(500 \mathrm{~mL}), \quad 7: 3 \quad(500 \mathrm{~mL}), \quad 6: 4 \quad(500 \mathrm{~mL}), \quad 4: 6 \quad(500 \mathrm{~mL}), \quad 3: 7$ $(500 \mathrm{~mL})$, and acetone $300 \mathrm{~mL}$ to yield 68 fractions. Fractions of $50 \mathrm{~mL}$ were collected and monitored by TLC. The fractions A1-20 (2.4 g), A21-31 (2.7 g), A32-41 (2.7 g), A42-49 (2.1 g), A50-55 $(3.8 \mathrm{~g})$, A56-61 $(1.1 \mathrm{~g})$, and A62-68 (3.5 g) were combined. These seven fractions were tested in paw edema model using 48/ 80 as inducer.

Of the active fraction A32-41, $1.0 \mathrm{~g}$ was fractionated by VLC on RP-18 (40-60 $\mu \mathrm{m}$, Merck) column (B) using a step gradient of acetonitrile-water $1: 1(200 \mathrm{~mL}), 7: 3(800 \mathrm{~mL}), 8: 2(200 \mathrm{~mL})$, acetonitrile $(100 \mathrm{~mL})$, and $\mathrm{MeOH}(300 \mathrm{~mL})$ as mobile phase to obtain 19 fractions (100 mL). Fractions B1-9, B10-15, and B16-19 were combined. Fraction B10-15 was chromatographed by VLC on RP18 (40-60 $\mu \mathrm{m}$, Merck) column (C) using a step gradient of acetonitrile-water $7: 3(800 \mathrm{~mL})$, acetonitrile $(400 \mathrm{~mL})$, and $\mathrm{MeOH}$ $(400 \mathrm{~mL})$ as mobile phase to obtain 16 fractions $(100 \mathrm{~mL})$. After TLC monitoring, two combined fractions B1-9/C1-10 (529 mg) and B16-19/C11-16 (464 mg) were obtained. Fraction B16-19/ C11-16 proved to be mixture of oleanolic acid and ursolic acid.

\section{Isolation of lignans}

Fraction A42-49 was fractionated by VLC on silica gel $(15 \mu \mathrm{m}$, Merck) column (D) with a gradient system of $n$-hexane-acetone $(90: 10 \rightarrow 0: 100)$ to yield 70 fractions. Fraction D45-57 was chromatographed by VLC on RP-18 (40-60 $\mu \mathrm{m}$, Merck) column with a gradient system of acetonitrile-water $(1: 4 \rightarrow 4: 1)(E)$ to obtain

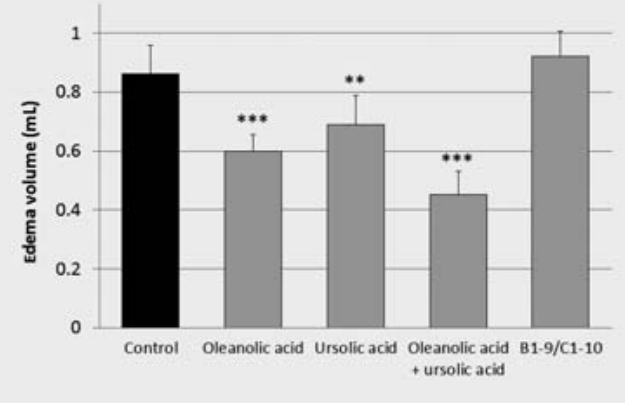

- Fig. 8 Effect of oleanolic acid (154 mg/kg), ursolic acid (96 mg/ $\mathrm{kg})$, mixture of oleanolic acid and ursolic acid imitating the composition of fraction A32-41 (154:96, $250 \mathrm{mg} / \mathrm{kg})$, and fraction B1-9/ C1-10 (250 mg/kg) on 48/80-induced rat paw edema (mean \pm SD; ${ }^{* * *} \mathrm{p}<0.001$ as compared with the control).

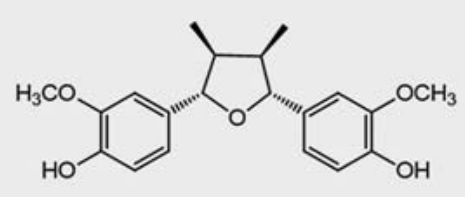

1

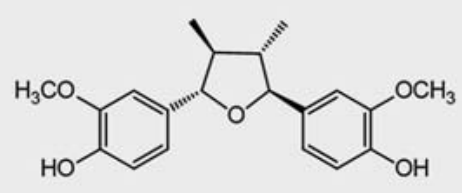

2

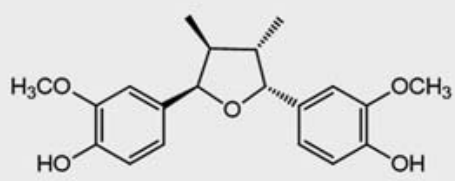

3

Fig. 9 Structures of the isolated lignans 1-3.

73 fractions. Preparative layer chromatographic purification of fraction E24-33 using silica gel plates and cyclohexane-dichloromethane-MeOH $(5: 15: 1)$ as eluent afforded compounds 1-3. Crystallization from $\mathrm{MeOH}$ fractions A50-55 and A56-61 afforded isorhamnetin.

Nectandrin $B(1)$ : amorphous solid; $[\alpha]_{D}^{25} 0$ (c $\left.0.40, \mathrm{CHCl}_{3}\right) ;{ }^{1} \mathrm{H}$ NMR and ${ }^{13} \mathrm{C}$ NMR, see Table $1 \mathrm{~S}$ (Supporting Information); ESIMS positive $\mathrm{m} / \mathrm{z} 345[\mathrm{M}+\mathrm{H}]^{+}, 327\left[\mathrm{M}+\mathrm{H}-\mathrm{H}_{2} \mathrm{O}\right]^{+}, 295[\mathrm{M}+\mathrm{H}-$ $\left.\mathrm{CH}_{3} \mathrm{OH}\right]^{+}, 221[\mathrm{M}+\mathrm{H} \text { - hydroxy-methoxyphenyl }]^{+}$.

$(+)$-Fragransin $A_{2}(2)$ : amorphous solid; $[\alpha]_{D}^{25}+78$ (c 1.0, $\mathrm{CHCl}_{3}$ ); ${ }^{1} \mathrm{H}$ NMR and ${ }^{13} \mathrm{C}$ NMR, see Table 15 (Supporting Information); ESIMS positive $\mathrm{m} / \mathrm{z} 345[\mathrm{M}+\mathrm{H}]^{+}, 327\left[\mathrm{M}+\mathrm{H}-\mathrm{H}_{2} \mathrm{O}\right]^{+}, 295[\mathrm{M}+\mathrm{H}$ $\left.-\mathrm{CH}_{3} \mathrm{OH}\right]^{+}, 221[\mathrm{M}+\mathrm{H} \text {-hydroxy-methoxyphenyl }]^{+}$. 
(-)-Saucernetindiol (3): amorphous solid; $[\alpha]_{D}^{25}-35$ (с 0.1 , $\mathrm{CHCl}_{3}$ ); ${ }^{1} \mathrm{H}$ NMR, see Table $1 \mathrm{~S}$ (Supporting Information); ESIMS positive $\mathrm{m} / \mathrm{z} 345[\mathrm{M}+\mathrm{H}]^{+}, 327\left[\mathrm{M}+\mathrm{H}-\mathrm{H}_{2} \mathrm{O}\right]^{+}, 295[\mathrm{M}+\mathrm{H}-$ $\left.\mathrm{CH}_{3} \mathrm{OH}\right]^{+}$.

\section{HPLC-UV analysis}

Oleanolic acid and ursolic acid content of fraction A32-41 was measured by HPLC on a LiChrospher 100, RP-18 $(4 \times 250 \mathrm{~mm}$, $5 \mu \mathrm{m})$ column using $\mathrm{MeOH}$-phosphate buffer $(0.03 \mathrm{M}, \mathrm{pH} 2.8)$ $88: 12$ as eluent at a flow rate of $1 \mathrm{~mL} / \mathrm{min}$. Calibration curves were made by diluting stock solution of ursolic acid $(300 \mu \mathrm{g} / \mathrm{mL})$ and oleanolic acid $(290 \mu \mathrm{g} / \mathrm{mL})$. Peaks were detected at $210 \mathrm{~nm}$.

\section{Anti-inflammatory test}

Animals: This study was approved by the Committee on Animal Research at the University of Szeged, Hungary (IV/141/2013, issued on January 8, 2013). A colony of $160200 \mathrm{~g}$ male SpragueDawley rats (Charles River Laboratories), fed with commercial rodent pellets and tap water, was used. Animals were housed in groups of five at controlled room temperature $\left(22 \pm 1^{\circ} \mathrm{C}\right)$ and maintained under an alternating $12 \mathrm{~h}$ light/ $12 \mathrm{~h}$ dark cycle (lights on at 6:00 am.).

Paw edema test: Fractions suspended in $5 \mathrm{~mL}$ methylcellulose gel (2\%) or $500 \mathrm{mg} / \mathrm{kg}$ dry extracts were given to rats per os. Since the main aim of the study was the identification of the active substances responsible for the action, and dose-response relationships were not considered. Therefore, one single and efficiently high dose was given for all tested extracts or fractions. The acute hind paw edema was induced by subplantar injection of the proinflammatory agents $(48 / 803 \mu \mathrm{g}$, bradykinin $5 \mu \mathrm{g}$, serotonin $5 \mu \mathrm{g}$, histamine $100 \mu \mathrm{g}$, carrageenan $500 \mu \mathrm{g}$, dextran [200,000 DA] $900 \mu \mathrm{g}$; in $0.1 \mathrm{~mL}$ saline) $1 \mathrm{~h}$ after the administration of extracts or positive control cetirizine. The contralateral foot was injected with isotonic saline. The rat paw volume was measured using digital plethysmometer $30 \mathrm{~min}$ (48/80, bradykinin, serotonin), 60 min (histamine, dextran), or 360 min (carrageenan) after administration of the pro-inflammatory agents. Cetirizine $(50 \mathrm{mg} /$ $\mathrm{kg}$ ) was used as a reference agent. All chemicals (at least $98 \%$ purity or molecular biology grade) were purchased from SigmaAldrich.

\section{Statistical analysis}

Statistical analyses were performed with Prism 4.0 software (GraphPad). Differences between the groups were assessed by two-way analyses of variance followed by the Newman-Keuls post hoc test. The criterion for statistical significance was $p<0.05$. All values are expressed as means of at least six values \pm SD.

\section{Supporting information}

Thin layer chromatogram and the effect of chloroform peel extract and fractions $\mathrm{A} 1-20$ to $\mathrm{A} 62-68$, and ${ }^{1} \mathrm{H}$ and ${ }^{13} \mathrm{C}$ NMR data of nectandrin $B(1)$, fragransin $A_{2}(2)$, and saucernetindiol (3) in $\mathrm{CD}_{3} \mathrm{OD}$ are available as supporting information.

\section{Acknowledgements}

Financial support from the Hungarian Scientific Research Fund (OTKA K109846) and Economic Development and Innovation Operative Program GINOP-2.3.2-15-2016-00012 are gratefully acknowledged. D. Rédei is a grantee of the János Bolyai Research Fellowship of the Hungarian Academy of Sciences. This paper is dedicated to Professor Dr. Max Wichtl in recognition of his outstanding contribution to pharmacognosy research.

\section{Conflict of Interest}

All authors declare no conflicts of interest.

\section{References}

[1] Olas B. Sea buckthorn as a source of important bioactive compounds in cardiovascular diseases. Food Chem Toxicol 2016; 97: 199-204

[2] Liu H, Zhang W, Dong S, Song L, Zhao S, Wu C, Wang X, Liu F, Xie J, Wang J, Wang Y. Protective effects of sea buckthorn polysaccharide extracts against LPS/d-GalN-induced acute liver failure in mice via suppressing TLR4-NF-KB signaling. J Ethnopharmacol 2015; 176: 69-78

[3] Suryakumar G, Gupta A. Medicinal and therapeutic potential of sea buckthorn (Hippophae rhamnoides L.). J Ethnopharmacol 2011; 138: 268-278

[4] Yasukawa K, Kitanaka S, Kawata K, Goto K. Anti-tumor promoters phenolics and triterpenoid from Hippophae rhamnoides. Fitoterapia 2009; 80: $164-167$

[5] Yuan H, Zhu X, Wang W, Meng L, Chen D, Zhang C. Hypoglycemic and anti-inflammatory effects of seabuckthorn seed protein in diabetic ICR mice. Food Funct 2016; 7: 1610-1615

[6] Park YH, Lim SH, Ham HJ, Kim HY, Jeong HN, Kim KH, Kim S. Isolation of anti-inflammatory active substance $\beta$-sitosterol from sea buckthorn (Hippophae rhamnoides L.) stem. Han'guk Sikp'um Yongyang Kwahak Hoechi 2010; 39: 980-985

[7] Szebeni A. Mégis gyógyítható az allergia. Available at http://mno.hu/ migr_1834/megis-gyogyithato-az-allergia-761825. Accessed January 21, 2017

[8] Anonymous. Homoktövissel az allergia ellen. Available at http://homoktoviswebaruhaz.hu/homoktovissel-az-allergia-ellen/. Accessed January 21, 2017

[9] Hu HB, Zheng XD, Jian YF, Liu JX, Zhu JH. Constituents of the root of Anemone tomentosa. Arch Pharm Res 2011; 34: 1097-1105

[10] Gnoatto SCB, Dassonville-Klimpt A, Nascimento S, Galéra P, Boumediene K, Gosmann G, Sonnet P, Moslemi S. Evaluation of ursolic acid isolated from llex paraguariensis and derivatives on aromatase inhibition. Eur J Med Chem 2008; 43: 1865-1877

[11] Nguyen PH, Le TVT, Kang HW, Chae J, Kim SK, Kwon K, Seo DB, Lee S], Oh WK. AMP-activated protein kinase (AMPK) activators from Myristica fragrans (nutmeg) and their anti-obesity effect. Bioorg Med Chem Lett 2010; 20: 4128-4131

[12] Hattori M, Hada S, Kawata Y, Tezuka Y, Kikuchi T, Namba T. Constituents of mace. Part II. New 2,5-bis-aryl-3,4-dimethyltetrahydrofuran lignans from the aril of Myristica fragrans. Chem Pharm Bull 1987; 35: 33153322

[13] Hanessian S, Reddy G], Chahal N. Total synthesis and stereochemical confirmation of manassantin A, B, and B1. Org Lett 2006; 8: 5477-5480

[14] Rothschild AM. Mechanisms of histamine release by compound $48 / 80$. Br J Pharmacol 1970; 38: 253-262

[15] Morris C]. Carrageenan-induced paw edema in the rat and mouse. Methods Mol Biol 2003; 225: 115-121 
[16] Zheng RX, Xu XD, Tian Z, Yang JS. Chemical constituents from the fruits of Hippophae rhamnoides. Nat Prod Res 2009; 23: 1451-1456

[17] Nadinic E, Gorzalczany S, Rojo A, van Baren C, Debenedetti S, Acevedo C. Topical anti-inflammatory activity of Gentianella achalensis. Fitoterapia 1999; 70: 166-170

[18] Gautam R, Jachak SM. Recent development in anti-inflammatory natural products. Med Res Rev 2009; 29: 767-820

[19] Tsuruga T, Chun YT, Ebizuka Y, Sankawa U. Biologically active constituents of Melaleuca leucadendron: Inhibitors of induced histamine release from rat mast cells. Chem Pharm Bull 1991; 39: 3276-3278

[20] Tang GH, Chen ZW, Lin TT, Tan M, Gao XY, Bao JM, Cheng ZB, Sun ZH, Huang G, Yin S. Neolignans from Aristolochia fordiana prevent oxidative stress-induced neuronal death through maintaining the $\mathrm{Nrf} 2 / \mathrm{HO}-1$ pathway in HT22 cells. J Nat Prod 2015; 78: 1894-1903

[21] Yang B, Linko AM, Adlercreutz H, Kallio H. Secoisolariciresinol and matairesinol of sea buckthorn (Hippophae rhamnoides L.) berries of different subspecies and harvesting times. I Agric Food Chem 2006; 54: 80658070

[22] Nishiwaki H, Nakayama K, Shuto Y, Yamauchi S. Synthesis of all stereoisomers of 3,3'-dimethoxy-7,7'-epoxylignane-4,4'-diol and their plant growth inhibitory activity. J Agric Food Chem 2014; 62: 651-659

[23] Song JS, Kim EK, Choi YW, Oh WK, Kim YM. Hepatocyte-protective effect of nectandrin B, a nutmeg lignan, against oxidative stress: role of Nrf2 activation through ERK phosphorylation and AMPK-dependent inhibition of GSK-3 $\beta$. Toxicol Appl Pharm 2016; 307: 138-149

[24] Hien TT, Ki SH, Yang JW, Oh WK, Kang KW. Nectandrin B suppresses the expression of adhesion molecules in endothelial cells: role of AMP-activated protein kinase activation. Food Chem Toxicol 2014; 66: 286-294

[25] Zhai H, Inoue T, Moriyama M, Esumi T, Mitsumoto Y, Fukuyama Y. Neuroprotective effects of 2,5-diaryl-3,4-dimethyltetrahydrofuran neolignans. Biol Pharm Bull 2005; 28: 289-293 